\title{
Developing ecostacking techniques for pollen beetle management in oilseed rape
}

\author{
H. M. T. Hokkanen ${ }^{1} \cdot$ I. Menzler-Hokkanen ${ }^{1}$
}

Received: 14 August 2018 / Accepted: 1 October 2018 / Published online: 29 October 2018

(c) The Author(s) 2018

\begin{abstract}
In this review, we examine how the principles of ecostacking could be used to manage the pollen beetle Brassicogethes aeneus in oilseed crucifer crops. We further describe hindrances preventing progress of keeping the pest under full biological control across Europe, and for other similar pest management situations. Ecological processes at different levels need to be considered and understood. The beneficial functions, which the various ecosystem service providers offer, need to be combined and exploited in an additive or synergistic manner, i.e., "ecostacked." Levels to consider include landscape and off-crop habitats (e.g., field margins) and their effects on pest management in the rapeseed crop; and possibilities to generate the key ecosystem services within the crop itself; for example, by vegetation management (e.g., undersowing, variety mixtures, companion and trap crops), soil management (biotic and abiotic; fostering and steering soil microbial communities to benefit biocontrol), and crop management, including crop protection treatments and their impacts on ecosystem service provision. All these processes affect the populations of the pollen beetle. Abundant information exists about most of the key processes important in this context. Utilizing this knowledge and stacking the various beneficial ecosystem service functions into a comprehensive management strategy for the pollen beetle, has not been attempted nor described. After illustrating the potential of ecostacking in solving crop protection problems, as it is apparent in the case of the pollen beetle, we analyze a situation where our approach was "lost in translation". The European Union Horizon 2020 program chose to support our vision of ecostacking with a 10 million euro grant. Administrative decisions by the coordinating university (not to accept to host the grant), and subsequent failure of the European Commission and its Research Executive Agency to demonstrate leadership on issues of research policy, integrity, and ethics in the handling of the project, resulted in a shift of emphasis away from solutions based onintegrative biocontrol.
\end{abstract}

Keywords Brassicogethes aeneus · Conservation biological control · Copyright · Ecosystem services · Intellectual property rights $\cdot$ Research policy

\section{Introduction}

A comprehensive approach is necessary in developing cropping systems to ensure that the beneficial services of functional biodiversity and ecosystem service providers (ESP)

Handling Editor: Yulin Gao.

Electronic supplementary material The online version of this article (https://doi.org/10.1007/s11829-018-9650-9) contains supplementary material, which is available to authorized users.

H. M. T. Hokkanen

heikki.hokkanen@helsinki.fi

1 Department of Agricultural Sciences, University of Helsinki, Helsinki, Finland to agricultural production are exploited to their full potential. We have proposed to maximize the benefits that can be accrued from ecosystem services in cropping systems by a process termed "ecostacking" (Hokkanen 2017; Hokkanen and Menzler-Hokkanen 2018a). Stacking implies here to combine in an additive or synergistic manner the beneficial services of functional biodiversity from all levels and types. In this approach, the various ecosystem service providers are fully integrated with the rest of the cropping system including agronomic practices. The ecosystem service providers involved include many types of organisms such as beneficial arthropods, vertebrates, microbes, and plants. Insects, mites, and spiders function not only as predators and parasitoids for the control of pests, but also as seed feeders and other specialist herbivores for weed control, and as pollinators of 
plants. Vertebrates such as small mammals, bats, and birds can function as seed feeders and predators of pests, while microbes provide invaluable ecosystem services including pest, disease, and weed control either directly as components of suppressive soils, or as colonizers of plants as endophytes or as epiphytic microbial flora. Soils suppressive to plant pathogens have long been known (e.g., Hornby 1983; Schlatter et al. 2017), but the potential of soils to be suppressive to insect pests has not been addressed (but see Hokkanen and Menzler-Hokkanen 2017, 2018a, b). The role of endoand epiphytic micro-organisms on plants, and their function in steering arthropod-plant interactions, is currently being intensively studied, while the utilization of microbe-mediated bottom-up effects in crop protection is only beginning to emerge (Shikano et al. 2017). The concept of plants providing ecosystem services related to pest, disease, and weed management, includes the crop plants themselves (e.g., via the benefits of genotypic diversity, and the ability to activate induced resistance mechanisms), companion crops (e.g., trap crops, intercrops, undersown crops), and plants providing nectar and pollen resources to beneficial arthropods.

In order to decide which techniques can best be used to support the most essential ESP functions in each specific cropping situation, it is necessary to (i) determine the role of the ESP under real field conditions in providing the biocontrol, pollination, and other ecosystem services; (ii) determine the most reliable and cost-effective sources of ESP either from the surrounding off-crop habitats, or from sources within the crop; (iii) investigate the possibilities of enhancing functional ESP by utilizing all possible levels of biodiversity in the cropping system (ranging from molecular and genetic levels to microbial, vegetation, and landscape level) and stacking these to optimise the effect; and to (iv) ensure that the agricultural system as a whole is supporting these processes, for example, by replacing toxic pesticides with biocontrol products and biorational pesticides, and by ensuring that the pesticides and other techniques, which still need to be used, do not harm the ESP.

In this review, we examine how the principles of ecostacking could be used to manage the pollen beetle Brassicogethes aeneus in oilseed crucifer crops, and some hindrances preventing progress in what we consider as an easily achievable target of keeping the pest under full biological control across Europe.

\section{Principles of ecostacking in the context of pollen beetle management}

\section{Landscape level processes}

How the spatio-temporal dynamics of the key organisms involved in pollen beetle management is affected by agricultural landscapes, is poorly studied and not well understood. The beetle itself overwinters as adult, and needs off-crop habitats for overwintering, selecting suitable sites within a range of several kilometers from the rapeseed fields. The quality of overwintering sites undoubtedly affects the survival rate of the beetle, which can vary enormously. Hokkanen (1993) measured an overwintering survival rate of only $2-4 \%$ for a natural population in Finland, while later studies have found much higher survival rates (up to $20 \%$ in Northern Germany and 10-15\% in Finland; Hokkanen, unpublished). Furthermore, the presence or absence of early flowering herbaceous plants at the overwintering site, offering pollen food to the beetles after emergence from hibernation, is expected to greatly influence pollen beetle survival. The beetles become active after temperatures rise to about $+5^{\circ} \mathrm{C}$ or above, but cannot fly away from the hibernation site until the temperature reaches about $+12^{\circ} \mathrm{C}$ (Mauchline et al. 2017). In the absence of pollen food, they face starvation unless they are able to fly away to early flowering spring plants such as dandelions. The beetles are strong fliers (up to $15 \mathrm{~km}$ measured, Taimr et al. 1967) and are able to optimize habitat use for their benefit within the broad landscape.

In contrast, the key natural enemies-hymenopteran parasitoids - are relatively little affected by landscape features. Main parasitoids overwinter as pupae in the soil of the rapeseed field, and emerge in the spring at the time of start of bud formation in the crop. Landscape affects their capacity to find and parasitize the pollen beetle larvae at least in two ways: (i) depending on crop rotation patterns, the next year's rapeseed fields may be far away from the previous year's fields. In that case, the landscape will affect the ability of the parasitoids to find the new fields of rapeseed, and increase mortality in transit; (ii) availability of floral resources to provide nectar nutrition to the parasitoids searching for the target habitat and the host larvae in the new rapeseed fields (Hatt et al. 2018).

Landscape has been shown to significantly affect the level of pollen beetle parasitism in rapeseed, and consequently, the damage caused by the pest: parasitism increases linearly as the proportion of uncultivated land within $1.5 \mathrm{~km}$ of the rapeseed field increases, and the amount of damaged buds decreases linearly at the same time (Thies and Tscharntke 1999).

Studies in Finland revealed the existence of regional level processes that synchronize host-parasitoid dynamics over large geographical areas (Hokkanen 2006). Data on annual percent parasitism of the pollen beetle larvae by Phradis morionellus (Ichneumoniidae) were collected in Finland for 11 years (1985-1995) from 35 to 70 different locations (13 regions) covering the total area of rapeseed cropping in Finland. Correlation analysis of the time-series data for the 13 regions revealed that the parasitoid dynamics follow 
a surprising pattern, being in synchrony over several large regions, but varying widely between these larger regions (more than $100 \mathrm{~km}$ in diameter). It has been suggested (Hokkanen 2006) that only edaphic and climatic factors can explain such regional patterns, and indeed, the boundaries of relief pattern types, and those of biotic zones in Southern Finland are similar to the approximate boundaries for the parasitism dynamics (Hokkanen 2006).

In the rapeseed system, improving ecosystem service provision in the target crop by optimizing provision of off-crop resources, involves provision of habitat, food, and alternative hosts for crop pollinators and natural enemies of crop pests. Providing early-flowering resources near the target crop will attract and maintain pollinators to the crop vicinity before focal crop flowering period, enabling better pollination. Late-flowering resources support pollinators after crop flowering, enabling pollinators to finish the season cycle. Likewise, early flowering resources support natural enemies of crops pests when resources are scarce, helping to buildup natural enemy populations in the crop early enough to prevent pest outbreaks, and late-flowering resources provide food, habitat, and alternative prey species after mass-flowering crops have finished blooming, therefore, promoting better survival of natural enemies for the next season.

\section{Role of field margins and trap crops}

Besides the obvious connection of field margins, and specifically sown trap crops, to the landscape-level processes discussed above, these off-crop elements can facilitate further benefits for ecostacking purposes. Planting of crops in proximity can improve pollination and pest control, provide habitat for farmland biodiversity, and maximize use of space to increase overall crop productivity (Skellern and Cook 2018). Trap crops (Hokkanen et al. 1986; Hokkanen 1991; Shelton and Badenes-Perez 2006) can be used directly for pest management, and can facilitate optimally timed delivery of emerging biocontrol technologies such as entomovectoring with insect pathogens (Hokkanen and Menzler-Hokkanen 2007; Hokkanen et al. 2015) and RNAi-products (Hokkanen and Menzler-Hokkanen 2018c). Timing in this context is critical, and trap cropping in the spring as well as in the autumn needs to be considered. Autumn trap crops may be easier to implement (e.g., less competing flowering plants) and can be superior for example in delivering next generation biopesticides based on RNAi (Hokkanen and MenzlerHokkanen 2018c). In the spring, turnip rapeseed can effectively be used as a trap crop for protecting oilseed rape from pollen beetle attack (Hokkanen 1989).

\section{In-field botanical diversity}

Cropping systems based on designed ecological interventions such as mulches or species or variety mixtures have several advantages, including higher yield quality and stability, improved pest, weed, and disease control, enhanced ecosystem services, and greater profitability (Balzan 2017; Schröder et al. 2017). In general, variety mixtures can increase yield stability and suppress insect pests (Grettenberger and Tooker 2017).

Species or variety mixtures probably have never been tried or considered in the context of providing protection against the damage by the pollen beetle. Although there are distinct differences between pollen beetle preferences for different crucifer oilseed species (Ekbom and Borg 1996), this may not be useful for limiting pollen beetle damage in practice. Very little information is available concerning varietal preference (but see Hervé et al. 2014; Hervé and Cortesero 2016).

Possible impact on pest control in rapeseed of intercropping with various species clover was studied in Finland (Perälä 1995). Strip intercropping with $50 \mathrm{~cm}$ broad strips of rapeseed alternating with $50 \mathrm{~cm}$ strips of four different species of clover was compared with rapeseed monoculture. Differences were neither shown for the number of pollen beetle adults or larvae per plant, nor in percent-parasitism by parasitic wasps, nor in the activity density of predatory ground beetles or spiders. The crop yields/ha (for the rapeseed strips in the intercrop-treatment) were equal, but the production of second generation pollen beetles $/ \mathrm{m}^{2}$ was significantly higher (more than double) in the monocrop than in the intercrop system (Perälä 1995; Hokkanen 2005). This was explained by the higher predator to prey ratio affecting the pollen beetles during pupation and adult emergence in the intercrop system.

Hokkanen and Menzler-Hokkanen (2017, 2018a) argue for the ecological benefits of growing white clover as an undersown crop in spring rapeseed in Finland. Based on several years of practical field data (unpublished), it is clear that white clover as undercrop can effectively suppress weeds in the rapeseed growing system, and provides additional benefits for soil processes including nitrogen fixation and increasing essential functional biodiversity in the system (see next section).

\section{Soil biotic and abiotic properties}

Soil properties and management, along with soil cover management, is likely a key factor in determining the extent and impact of in-crop generation of ESP, affecting greatly the soil and epigeial ESP fauna (predatory mites, ground beetles, spiders, overwintering parasitoids, entomopathogenic 
nematodes, etc) and flora (entomopathogenic fungi and other microbes). At the landscape level, abiotic factors such as soil type and texture via their differential impact on parasitoid dynamics, are suspected as the main drivers of the regional synchronization of patterns in pollen beetle parasitism (Hokkanen 2006).

Hokkanen and Menzler-Hokkanen (2018a) proposed to develop the concept of "insect pest suppressive soils," and provided data on the occurrence and importance of soilborne insect pathogens in pest population suppression. Agricultural fields usually harbour only low numbers of beneficial insect antagonists such as entomopathogenic nematodes (EPN) and fungi (EPF), so that their role in pest population dynamics currently is negligible. Simple improvements in field and crop management, however, can quickly increase the numbers of EPN and EPF to levels that will lower the peak pest populations (Hokkanen and Menzler-Hokkanen 2018a).

Concerning specifically the known pathogens of main oilseed Brassica pests, only entomopathogenic nematodes (EPN) and fungi (EPF) are widely distributed (Hokkanen et al. 2003). The EPF usually infecting pollen beetle are facultative pathogens, widely distributed in soils throughout the world, and occurring throughout the Brassica oilseed crops. Several studies have been published concerning their distribution in America, Australia, and Europe (e.g., St Leger et al. 1992; Roberts and St Leger 2004), often to find general relationship of these pathogens with the soil type, preferences of habitat type, and other abiotic and biotic factors affecting their abundance and role as insect antagonists (Vänninen 1996). However, their reported natural abundances in agricultural fields have always been low (e.g., Vänninen et al. 1989).

Most thoroughly studied EPF for potential control of OSB pests include Beauveria bassiana and Metarhizium anisopliae. Both taxa have repeatedly been shown to kill effectively the adults and larvae of the pollen beetle (e.g., Butt et al. 1994; Husberg and Hokkanen 2001; Hokkanen et al. unpublished). In the field, treatments with EPF have not reduced the new generation pollen beetle numbers, neither via soil treatment nor via fungal sprays (Hokkanen 1993). However, soil treatments with EPF have caused dramatic indirect effects via increased overwintering mortality. Soil treatment with B. bassiana reduced overwintering survival of beetles developed under unlimited food resources by $50 \%$ (from 14 to $7 \%$ ), compared with the untreated control.

The weight (fat reserves) of the beetles is a crucial factor explaining overwintering mortality of B. aeneus (Hokkanen 1993). Soil treatment with B. bassiana lowered the weight of pollen beetles developed under unlimited food resources by $16 \%$, which alone is likely to be enough to result in the measured reduction in survival by $50 \%$. However, beetles developing under normal conditions (collected from the wild) and under shortage of autumn food sources (pollen plants), were before overwintering $46 \%$ lighter than the experimental reference beetles. This lighter weight resulted in only 3\% survival over the winter (Hokkanen 1993). If we assume that all rapeseed fields would contain effective levels of EPF either naturally or via augmentation, the pollen beetle populations would be expected to crash completely during the overwintering (survival would be reduced from $3 \%$ to maybe around $1 \%$ ).

In contrast to the effect of EPF, direct mortality of pollen beetles in the field caused by entomopathogenic nematodes can be very high. Augmenting the field soil of rapeseed with Steinernema feltiae at the rates of 0.1-1.0 million infective juveniles (IJ)/ $\mathrm{m}^{2}$ resulted in $95 \%$ reduction in the number of emerging pollen beetle adults (Hokkanen 2008). This shows a very high potential of the field soil to be suppressive to the pollen beetle, provided that adequate levels of antagonists such as EPF and EPN are present in the soil (Fig. 1) (Menzler-Hokkanen and Hokkanen 2005).

Plant-associated microbes and their metabolites have been shown to have the potential to significantly alter the above-ground insect community, as they can affect virtually every type of plant-plant, plant-pathogen, plant-beneficial organism, and plant-herbivore interactions (Pineda et al. 2017; Prieto et al. 2017). A number of fungal and bacterial strains that occur naturally as part of the root microbiome, or indeed are used for biocontrol (e.g., Trichoderma spp., Bacillus spp., mycorrhizal fungi, Pochonia spp. and Paecilomyces spp.), have an indirect effect against pests via the plant, by activating defense response pathways. This induction can in some cases be more effective than the biocontrol agent itself, and offers large but unexplored potential for ecostacking in the rapeseed cropping system.

\section{The role of pesticides}

Insecticide sprays to control peak population densities of the pollen beetle is routinely used in rapeseed cropping systems (Tiilikainen and Hokkanen 2008). In situations where

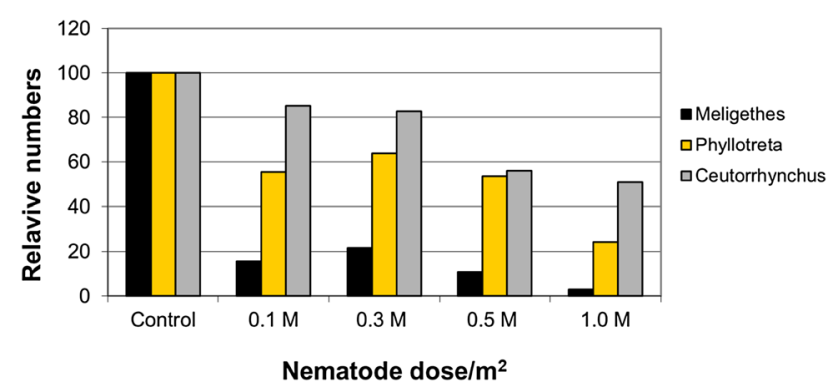

Fig. 1 Relative effect of Steinernema feltiae -treatments at different doses on some rapeseed target pests in Finland in 2004. Water treated control $=100$ Modified after Hokkanen (2008) 
the parasitoid occurrence and impact is low, as in winter oilseed rape in Germany, insecticide applications were not observed to affect significantly the parasitization of pollen beetle larvae by its ichneumonid parasitoids, regardless whether applied at the bud stage, at the beginning of flowering, or at full flowering (Brandes et al. 2018). In spring sown rapeseed, parasitoids often occur at much higher levels (e.g., Hokkanen et al. 1988; Veromann et al. 2009) insecticide applications will affect parasitoids detrimentally if they take place close to flowering (Hokkanen et al. 1988). Spray window in Finland was determined to be before accumulated day-degrees reach 320 , normally at about mid-June; therefore, insecticide treatments prior to that were considered to be safe to parasitoids (Hokkanen et al. 1988).

An analysis of long-term patterns of pollen beetle parasitism in Finland revealed an interesting connection between the regularly occurring, severe crashes in percent-parasitism of the pollen beetle, and outbreaks of cereal aphids: parasitism levels always crash in years of aphid outbreaks (Hokkanen et al. unpublished). A strong negative correlation was found between pollen beetle parasitism level and the severity of cereal aphid attack, as well as between sales of the insecticide dimethoate (used to control aphids in cereals) and pollen beetle parasitism levels (Hokkanen et al. unpublished). It appears clear that in outbreak years of cereal aphids-about twice in a decade in Finland during the past several decades - the pollen beetle parasitoids are killed as the aphids are controlled with insecticide sprays. In crop rotations in Finland, spring oilseed crops are usually followed by spring cereals. Therefore, the pollen beetle parasitoids emerge in the following year from fields of spring cereals, usually exactly at the same time as aphids colonize the fields and are controlled if needed (around mid-June till end of June). It would be best not to spray insecticides in the fields, where rapeseed was grown in the previous year, in order to maximize the biocontrol of pollen beetle by its effective parasitoids.

Simulation models (Hokkanen and Kaukoranta, unpublished) show that parasitoids are capable of completely controlling the pollen beetles at levels much below economic thresholds; unless the crop management interferes and negates their impact. Crop spraying with insecticides and soil cultivation methods are the key factors in the current management, preventing effective natural control of the beetle by its parasitoids (see Fig. 2). Both of these can easily be modified to allow effective biological control (Hokkanen et al. 1988; Hokkanen 2008).

Insecticide treatments in general in the rapeseed ecosystem appear to have led to localized eradications of an important biotic regulator of the pollen beetle populations, the specific EPF Nosema meligethi, previously classified as Protozoa (Lipa and Hokkanen 1992; Hokkanen and Lipa 1995). Nosema meligethi is an intracellular obligate parasite

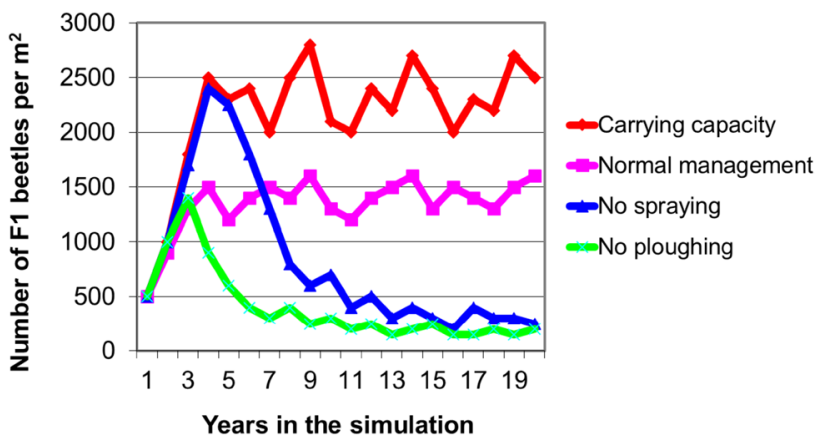

Fig. 2 The number of $\mathrm{F} 1$ generation pollen beetles produced per $\mathrm{m}^{2}$ in rapeseed fields, calculated on actual weather data for Finland for a 20-year period, under four different management scenarios affecting the capacity of parasitoids to keep the pollen beetle populations under biological control: (1) carrying capacity of the rapeseed plant (no management, no natural enemies present); (2) normal management with spraying at threshold densities, and normal soil tillage, parasitoids present; (3) same as 2, but no spraying at any time; (4) same as 2 , but no soil ploughing immediately after rapeseed growing (e.g., direct drilling of the following crop instead) Modified after Hokkanen (2008)

specific to the genus Meligethes. It is an ideal insect pathogen from a population dynamics point of view: it causes chronical disease with lowered fecundity and lifespan, and high overwintering mortality, and is transmitted both horizontally and vertically (Hokkanen and Lipa 1995). Lipa and Hokkanen (1992) studied the occurrence of N. meligethi across Europe. Samples of Meligethes spp. from 12 countries in Eastern and Western Europe were inspected for the occurrence of infection. A total of 13,910 individual beetles were checked, and of these, 561 were found to be infected $(4.03 \%)$. Infection was not detectable in samples from the UK, Germany, Sweden, or Switzerland. In contrast, the disease was found rather regularly in samples from Finland and from Eastern European countries. No obvious reason for this pattern of infection is known, but pesticide usage at or close to the sampling sites may play a role, because most samples from which Nosema was detected originated from areas where few pesticides are used.

Nosema infection was also shown to lower pollen beetle weights on the average by $13 \%$ - similar to the effect of soil treatment with $B$. bassiana - which is enough to explain the reported increases in the overwintering mortality of the beetles due to Nosema infection (Hokkanen and Lipa 1995).

\section{Biopesticides and entomovectoring}

Only a few options are available as potential biopesticides for the control of the pollen beetle. Besides EPF and EPN, no known microbial pesticides are effective against this beetle. With EPF sprays in the field, good reduction of the pest has been obtained. For example, M. anisopliae treatment 
caused $75 \%$ mortality in pollen beetle larvae (Hokkanen 2008). Reduction of pollen beetle larvae on the inflorescences, however, may not be interesting from practical crop protection point of view, because the main damage to the crop has already been done by the adults. Furthermore, even a high reduction in the size of the larval population is not likely to lower the population of the new generation emerging during the summer (Hokkanen 2000). Metarhizium sprays could possibly be used to kill adult pollen beetles in the spring via fungal sprays at the bud stage, but the best option might be to grow and treat an early flowering trap crop (e.g., turnip rape) with the EPF.

Targeted, precision delivery of microbiological control agents such as EPF has been developed in the last two-three decades to improve practical and economic efficiency of biocontrol agent use. Usually, managed pollinating insects such as honey bees and bumble bees are employed as vectors; hence the term "entomovector technology" (first used by Hokkanen and Menzler-Hokkanen 2007). The vectoring insects are loaded with the powdery biocontrol preparate at the exit from their hive, and while visiting the flowers of the target crop, they deliver the biocontrol agent onto the crop inflorescences (Hokkanen et al. 2015). As pollen beetles feed in open flowers, they are good targets for entomovectoring, because rapeseed flowers are highly attractive also to pollinators. These opportunities have been explored during the past 20 years.

Butt et al. (1998) report that honey bees foraging from a hive fitted with an inoculum dispenser at the entrance effectively delivered dry conidia of $M$. anisopliae to the flowers of oilseed rape in caged field plots. In both winter- and spring-sown rape experiments, a greater mortality of pollen beetles occurred in treated plots than in control plots. The mortality ( $61 \%$ on winter rape, $100 \%$ on spring rape) was greatest during peak flowering, when the feeding activity of both bees and beetles from the flowers was maximal, providing optimal conditions for inoculum dissemination and infection. Conidial sporulation occurred on a significant proportion of the dead pollen beetles.

Carreck et al. (2007) show in a later study that $M$. anisopliae, disseminated to the flowering canopy of oilseed rape by the honey bee, infect seed weevil adults and pollen beetle adults and larvae in the flowers. Subsequent mortality of adults of both species and the larvae of pollen beetle, following incubation in the laboratory was high, always exceeded $70 \%$, and a high proportion of cadavers showed external conidiation, confirming infection by M. anisopliae.

Experience so far shows that bees are more efficient than conventional sprayers in delivering the EPF inoculum to the pest infested flowers (Butt and Copping 2000). Entomovectoring improves targeting and provides cost-effective control of pests (see also Hokkanen et al. 2015), and can be adopted for improving pest management in rapeseed.
Entomovectoring may be most appropriate in connection with an early-flowering trap crop (Hokkanen 1991). Field experiments have indicated excellent potential for employing Brassica rapa as a trap crop for B. napus, as it flowers clearly earlier and is highly attractive to rapeseed pests, as well as to bees and other pollinators such as hoverflies (Fig. 3) (Hokkanen 1989a).

\section{Research policy undermining attempts to provide credible solutions to sustainability}

Developing ecostacking techniques for pollen beetle management would require a comprehensive approach, which combines all the processes described above, and other known factors into a single, functioning strategy. This is normally too demanding of an undertaking for a single researcher or a research group in an institution-but is typical of international research projects such as those funded by the European Union.

European agriculture requires alternative pest management strategies. Despite biocontrol knowledge and enthusiasm, the use of biocontrol-based solutions in open field in Europe is minimal. Political, administrative, and intellectual obstacles involved in expanding biocontrol to open fields are huge. For illustration, we describe, here, as a case study how a promising, pan-European research project with focus on ecostacking, was transformed from its original aspiration by a series of administrative and research policy decisions. As a result, a project initially based on integrated biocontrol, was lost in translation (see Menzler-Hokkanen, 2018, in this issue).

Handling the EU's Horizon 2020 biocontrol-founded project "EcoStack" illustrates lack of transparency concerning IP rights and copyright protection at the EU-level. The project proposal addressed the call SFS-28-2017, and was created, written (for the most parts), and submitted by

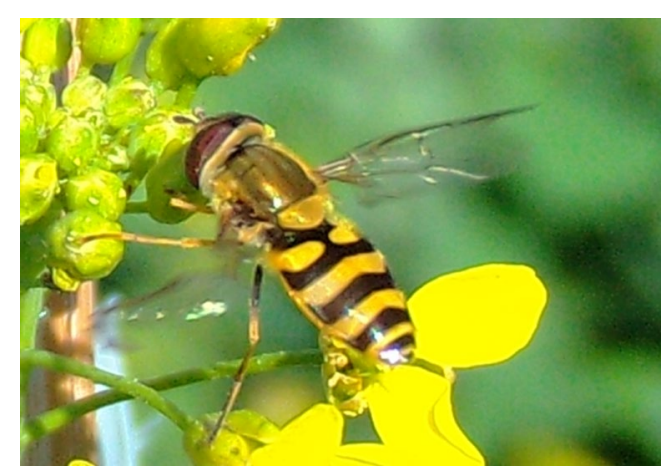

Fig. 3 Hoverfly, an important component in ecostacking, visiting rapeseed flowers. Photo by Leo Laaksonen 
the University of Helsinki (UH) research team led by the authors of this review. The $10 \mathrm{M} €$ research project EcoStack was approved for funding on 15 December 2017. The UH team, however, in the end was completely excluded from the project. While the EcoStack project was funded based on the ideas and texts of the original submission, in the final Description of Action, the names of the UH team members have been replaced by other names, and was presented to the EC without mentioning the original project coordinator (PC), or other UH authors of the proposal.

The IP and copyright of the original PC and of the UH research team covers the concept and name of EcoStack, and large parts of the text in the proposal. For example, the whole section on Project Management and the work-package on Policy Options and Dissemination with their innovations were completely written by the UH team. These sections are included in the funded version as originally proposed, but with the exception that the original author's names are replaced by other names, mainly from the University of Naples. In our view, this violates the IP and copyright rights of the UH team, is ethically wrong, and alters the direction of the funded research.

With reference to the "chronology of translation mistakes between a promising call text and academic reality", as listed in the Editorial of Menzler-Hokkanen (2018, this issue), several points need to be discussed here more thoroughly. These include (i) the dynamics of forming the consortium around the original ideas of the coordinating team; (ii) the role of the coordinating institution-University of Helsinki-and in particular of the persons in charge of science policy decisions at the university (Dean of the faculty of agriculture and forestry, and the Rector of UH); (iii) behavior of the consortium partners when salvaging of the project was at stake after UH's decision to withdraw from it; (iv) the exclusion process of UH team members from any role in the project after appointment of the new project coordinator (University of Naples); and (v) the passive role of the European Commission in addressing issues of research policy, integrity, and ethics in the context of the project EcoStack.

\section{Consortium formation}

The basic ideas forming the foundation of the EcoStackproject have been formed during the decades of experience of the original project coordinator $(\mathrm{HH})$ on biological control, ecology, and pest management. They were first formulated in an ERA-NET proposal called BioStack, and further developed within a NOVA University Network's $\mathrm{PhD}$-course series, coordinated by HH. With the H2020call SFS-28-2017 "Functional biodiversity - productivity gains through functional biodiversity: effective interplay of crop pollinators and pest predators", the original BioStackgroup decided to prepare and submit a proposal, coordinated by $\mathrm{HH}$. The UH team invited other researchers to join our consortium, sometimes based on suggestions from other consortium members. This is a standard procedure, but the dynamics needs to be understood as the background for the evaluation of further events in this case.

\section{The role of $\mathrm{UH}$ administration}

As explained by Menzler-Hokkanen (2018, this issue), the UH research administrators supported the project proposal preparation and the grant agreement preparation process. However, obtaining administrative signatures to project documents was difficult. Two days before the Commission deadline to sign the finalized Grant Agreement, the rector of UH decided that UH declines to host the grant. The Dean of the faculty for agriculture and forestry sent an official letter to the Commission (EC) that UH does not take the $10 \mathrm{M} €$ grant and will not host the EcoStack project. Internally, it was made clear to the $\mathrm{PC}(\mathrm{HH})$ that the order not to accept the project came directly from the Rector of UH, professor Jukka Kola. Officially, the excuse was, as expressed in the letter to the EC, the "encountered project management and legal incompetence issues" related to the project administration. This cannot be the real reason, as the PC and the UH team is among the most experienced participants in EUresearch projects at the university, having coordinated two previous EU-projects and participated in five others as WPleaders. Furthermore, management and legal support and direct participation in the project management by the UH administrative staff (from the research services) were agreed upon. The formulation of the letter sent to the EC seems to suggest that UH highest administration does not believe that its own staff, employed by its research services unit, is competent enough to handle an EU-project of this size.

The real reason in our opinion may lie in broader issues related to agricultural policy, and the kind of research, which $\mathrm{UH}$ wishes to promote in this context. The Rector of UH at the time of this decision was the professor of agricultural policy at UH. His decision steers the research policy at UH toward other types of solutions to acute problems in agriculture, unlike the clear wish from the EC to support the kind of research, which we proposed. In the aftermath of this process, the faculty of agriculture and forestry at UH now requires that all applications for research funding have to pass through internal acceptance to make sure they are in line with the chosen research policy and profile of the faculty. It appears that the tradition of universities being the place for "free, independent research", as heralded for centuries, is now abandoned. 


\section{The role of EcoStack consortium partners}

After the withdrawal of $\mathrm{UH}$ as the project coordinator, and as a partner in the EcoStack project, the $\mathrm{PC}(\mathrm{HH})$ was advised by the EC to seek another EcoStack beneficiary to host the project and to take over the UH research and the research team (Lara Passante, Head of Section, Research Executive Agency, EC; 15 April 2018). A series of in-depth negotiations followed, in which the Finnish EcoStack partners declined to host EcoStack in an apparent fear of possible reaction form UH to such an arrangement. The UH team was determined to retain the broad geographical coverage for the research tasks, as was requested in the call, and how it was proposed in the approved EcoStack description of work. For research in the boreal zone, only Finnish and Swedish partners can contribute and have field sites located in this zone. The Swedish University of Agricultural Sciences in Uppsala was very constructive and willing to host the project and UH's research, but needed time to sort out internal procedures before full commitment. As explained by Menzler-Hokkanen (2018, this issue), the University of Naples (UNA) interfered at that stage, and SLU stopped negotiations with the UH team.

What followed was an outright take-over of the EcoStack project by the UNA, including the person-months, research obligations, and funds initially allocated to UH. Examining the events in this process serves as an illustration of human behavior, and demonstrate sadly how long-term partnerships are forgotten and abandoned in the short-term economic and research interests of colleagues. In the take-over process, not a single partner ever expressed publically an opinion to retain the EcoStack project as it initially was designed, and that there are

Table 1 Distribution of the UH share of the EcoStack budget as additional resource allocation to several EcoStack partners (budget increases to the 11 partners over their original budgets)

\begin{tabular}{lc}
\hline Beneficiary & $\begin{array}{c}\text { Additional } \\
\text { funds in } €\end{array}$ \\
\hline University of Naples, Italy & 584,000 \\
Swedish University of Agricultural Sciences, Sweden & 183,000 \\
Institut supérieur d'agriculture Rhône-Alpes (ISARA), & 83,000 \\
$\quad$ France & \\
Rothamsted Research, United Kingdom & 80,000 \\
Jagiellonian University, Kraków, Poland & 61,000 \\
University of Turku, Finland & 58,000 \\
University of Aarhus, Denmark & 42,000 \\
University of Newcastle, United Kingdom & 30,000 \\
Julius Kühn Institute, Germany & 22,000 \\
University of Kassel, Germany & 15,000 \\
University of Coimbra, Portugal & 15,000 \\
University of Belgrade, Serbia & 15,000 \\
\hline
\end{tabular}

possibilities to keep the UH team involved. No support to the constructive proposals to solve the situation by the $\mathrm{UH}$ team was expressed. Instead, everyone kept silent while their loyalty to the new arrangement was bought by distributing the UH funds as additional funds to them, from the budget initially allocated to research and management at UH (see Table 1). Partners, who did not get additional funds, apparently were either not informed about what was going on (at least several Finnish partners were not informed by the new PC), or feared to express a different opinion in order not to be excluded from the project like the UH team, by the new PC (private communication with two Finnish EcoStack partners).

\section{Exclusion of UH team members}

Based on the advice from the EC (Lara Passante 15.4.2018), we considered it self-evident that the UH team members (HH, IMH) can participate in EcoStack research as employees at another beneficiary than the UH. This was expected also because much of the background IP and the copyrights to large sections of the proposal texts belong to the UH team, and cannot be just taken over by others without their involvement. At the negotiation stage, the proposed new PC promised verbally and in writing (e.g., on 17 and 18 April 2018) that both of us (HH, IMH) will have a position in the project, for example, at UNA, after everything is sorted out. However, after having been formally appointed as the PC, all these promises have been forgotten and any credible solutions to engage the UH team were flatly dismissed. Alternative scenarios to retain the research parts, which originally were allocated to be conducted in Finland (and in the boreal zone), were ignored by the new PC. Similarly, the EC stopped communicating with us, and the new PC explicitly forbids us to contact the Commission on EcoStack matters.

The complete exclusion of the UH team from executing the EcoStack project seriously violates the IP and copyright rights of the original PC and members of the UH team. According to Webster's (Random House 1991), plagiarism is defined as "the unauthorized use of the language and thoughts of another author and the representation of them as one's own." Furthermore, "copyright" are the exclusive rights, which the law confers on authors to maintain their own terms and conditions for using their intellectual property. In the approval process of the EcoStack process, the final submission of the Description of Action (DoA) was presented to the Commission without any mentioning of the $\mathrm{UH}$ team $(\mathrm{HH}, \mathrm{IMH})$ who created the project, and wrote large sections of the DoA. For example, the description of WP 10 "Policy options and dissemination of project results" (see Supplementary material) was completely written by the 
WP leader, I. Menzler-Hokkanen. The final submission version by the new PC in the Grant Agreement Preparation phase was identical, with the exception that I. MenzlerHokkanen's name was replaced with two Italian names. Similarly, elsewhere in the final submitted DoA, the names of Heikki Hokkanen and Ingeborg Menzler-Hokkanen had been replaced by other names. This is plagiarism by definition, and violation of our copyright rights, resulting in hijacking of our $10 \mathrm{M} €$ research project from us.

\section{The role of the European Commission}

The Research Executive Agency, the Directorate General for Research and Innovation, and the Directorate General for Agriculture and Rural Development of the European Commission distance themselves from the legal complexity of the issue, and claim "that the Commission and REA are not able to directly intervene in any intellectual property disputes between the consortium members". To settle these questions, the advice was to go to court (see quotations in Menzler-Hokkanen 2018, in this issue). Concerning any moral or ethical questions, the official reply was, "As regards the European Charter and Code for Researchers, we found no issue to be addressed under the remit of the Commission or REA."

It should be noted that the Ethics Helpdesk of the European Commission (https://ec.europa.eu/research/participan ts/portal/desktop/en/support/other_help_services.html) never replied to our queries about the questions of research ethics in this context, while the IPR Helpdesk explained the legal complexity of our case, and the lack of precedents in this type of situation. It is disappointing that the European Commission failed to demonstrate leadership in addressing issues of research policy, integrity, and ethics in the context of the project EcoStack, and allowed such an unprecedented takeover of a European research project.

The EC pretends not to realize that the current, funded EcoStack project differs significantly in spirit and approach from the proposal, which was selected for funding by the proposal evaluators after the second stage submission. A European research project is largely profiled through the expertise profile of its coordinator, which in the case of EcoStack originally was based on the PC's background and expertise in biological control, ecosystem ecology and functioning, and provisioning of ecosystem services. Key components of that expertise include trap crops (Hokkanen et al. 1986; Hokkanen 1991), new association biological control (Hokkanen and Pimentel 1984, 1989), entomovectoring (Hokkanen and Menzler-Hokkanen 2007; Hokkanen et al. 2015), integrated pest management (Hokkanen 2017; Menzler-Hokkanen and Hokkanen 2018), and insect pest suppressive soils (Hokkanen and Menzler-Hokkanen $2018 \mathrm{a}, \mathrm{b}, \mathrm{c})$. Most of these topics have been integrated in the formulation of the EcoStack project proposal and the DoA. In the takeover, the original PC was replaced by a $\mathrm{PC}$ with unquestionable expertise on the molecular physiology of insects, insect immunity, and immunosuppression, along with biotechnologies for insect control that can be developed based on this knowledge. In our view, this change in profile of the $\mathrm{PC}$, however, alters also the profile and vision for the whole project, and does not match the original intention of the call.

Acknowledgements We gratefully acknowledge support to our work on sustainable pest management from the EU-ERA-Net program C-IPM project "IPM4Meligethes," and from the Academy of Finland project "Resilient, productive, and sustainable cropping of cassava in SE Asia: utilizing bottom up effects to manage plant-herbivore-natural enemy interactions". Our concept of ecostacking has been influenced to some extent by colleagues participating in the preparation of a proposal to address the EU-call SFS-28-2017: Functional biodiversity-productivity gains through functional biodiversity: effective interplay of crop pollinators and pest predators.

Open Access This article is distributed under the terms of the Creative Commons Attribution 4.0 International License (http://creativeco mmons.org/licenses/by/4.0/), which permits unrestricted use, distribution, and reproduction in any medium, provided you give appropriate credit to the original author(s) and the source, provide a link to the Creative Commons license, and indicate if changes were made.

\section{References}

Balzan MV (2017) Flowering banker plants for the delivery of multiple agroecosystem services. Arthropod Plant Interact 11:743. https:// doi.org/10.1007/s11829-017-9544-2

Brandes M, Heimbach U, Ulber B (2018) Effects of insecticide application on parasitism rates of pollen beetle larvae (Brassicogethes aeneus (Fabricius)) by tersilochinae parasitoids. Arthropod Plant Interact. https://doi.org/10.1007/s11829-017-9580-y

Butt TM, Copping LG (2000) Fungal biological control agents. Pest Outlook 11:186-191. https://doi.org/10.1039/B008009H

Butt TM, Ibrahim L, Ball BV, Clark SJ (1994) Pathogenicity of the entomogenous fungi Metarhizium anisopliae and Beauveria bassiana against crucifer pests and the honey bee. Biocontrol Sci Technol 4:207-214

Butt TM, Carreck NL, Ibrahim L, Williams IH (1998) Honey-beemediated Infection of pollen beetle (Meligethes aeneus Fab.) by the insect-pathogenic fungus, Metarhizium anisopliae. Biocontrol Sci Tech 8:533-538. https://doi.org/10.1080/09583159830045

Carreck NL, Butt TM, Clark SJ, Ibrahim L, Isger EA, Pell JK, Williams IH (2007) Honey bees can disseminate a microbial control agent to more than one inflorescence pest of oilseed rape. Biocontrol Sci Technol 17:179-191. https://doi.org/10.1080/0958315060 0937485

Ekbom B, Borg A (1996) Pollen beetle (Meligethes aeneus) oviposition and feeding preference on different host plant species. Entomol Exp Appl 78:291-299

Grettenberger IM, Tooker JF (2017) Variety mixtures of wheat influence aphid populations and attract an aphid predator. Arthropod Plant Interact 11:133, https://doi.org/10.1007/s11829-016-9477-1

Hatt S, Uyttenbroeck R, Lopes T, Chen JL, Piqueray J, Monty A, Francis F (2018) Effect of flower traits and hosts on the abundance of 
parasitoids in perennial multiple species wildflower strips sown within oilseed rape (Brassica napus) crops. Arthropod Plant Interact https://doi.org/10.1007/s11829-017-9567-8

Hervé MR, Cortesero AM (2016) Potential for oilseed rape resistance in pollen beetle control. Arthropod Plant Interact 10:463-475. https://doi.org/10.1007/s11829-016-9438-8

Hervé MR, Delourme R, Leclair M, Marnet N, Cortesero AM (2014) How oilseed rape (Brassica napus) genotype influences pollen beetle (Meligethes aeneus) oviposition. Arthropod Plant Interact 8:383-392. https://doi.org/10.1007/s11829-014-9321-4

Hokkanen HMT (1989a) Biological and biotechnical control of the rape blossom beetle Meligethes aeneus F. Acta Entomol Fennica 53:25-29

Hokkanen HMT (1991) Trap cropping in pest management. Annu Rev Entomol 36:119-138. https://doi.org/10.1146/annur ev.en.36.010191.001003

Hokkanen HMT (1993) Overwintering survival and spring emergence in Meligethes aeneus: effects of body weight, crowding, and soil treatment with Beauveria bassiana. Entomol Exp et Appl 67:241-246

Hokkanen HMT (2000) The making of a pest: recruitment of Meligethes aeneus onto oilseed brassicas. Entomol Exp Appl 95:141-149

Hokkanen HMT (2005) Impact of predators on pollen beetle Meligethes aeneus on rapeseed in Finland. IOBC/WPRS Bull 27:295-298

Hokkanen HMT (2006) Phradis morionellus on Meligethes aeneus: longterm patterns of parasitism and impact on pollen beetle populations in Finland. IOBC/wprs Bull 29(7):187-192

Hokkanen HMT (2008) Biological control methods of pest insects in oilseed rape. EPPO Bull 38:104-109

Hokkanen HMT (2015) Integrated pest management at the crossroads: science, politics, or business (as usual)? Arthropod Plant Interact 9:543-545. https://doi.org/10.1007/s11829-015-9403-y

Hokkanen HMT (2017) Ecostacking: maximising the benefits of ecosystem services. Arthropod Plant Interact 11:741. https://doi. org/10.1007/s11829-017-9575-8

Hokkanen HMT, Lipa JJ (1995) Occurrence and dynamics of Nosema meligethi (Microsporida) in populations of Meligethes aeneus (Coleopera, Nitidulidae) in Finland. Entomol Fennica 6:11-18

Hokkanen HMT, Menzler-Hokkanen I (2007) Use of honeybees in the biological control of plant diseases. Entomol Res 37 (Suppl. 1), A62-A63, https://doi.org/10.1111/j.1748-5967.2007.00082.x

Hokkanen HMT, Menzler-Hokkanen I (2017) The use of entomopathogenic fungi in the insect pest management of Brassica oilseed crops. In: Reddy GVP (ed) Integrated management of insect pests on canola and other Brassica oilseed crops. CABI, Boston, pp 373-382

Hokkanen HMT, Menzler-Hokkanen I (2018a) Insect pest suppressive soils: buffering pulse cropping systems against outbreaks of Sitona weevils. Ann Entomol Soc Am. https://doi.org/10.1093/aesa/say019

Hokkanen HMT, Menzler-Hokkanen I (2018b) Urgent need to develop ecostacking techniques to enhance ecosystem services in cropping systems. Arthropod Plant Interact. https://doi.org/10.1007/s1182 9-018-9620-2

Hokkanen HMT, Menzler-Hokkanen I (2018c) Trap cropping as a delivery platform for RNAi-based targeted control of the pollen beetle Brassicogethes aeneus. Mitt Dtsch Ges Allg Angew Ent. 21 (in press)

Hokkanen H, Pimentel D (1984) New approach for selecting biological control agents. Can Entomol 116:1109-1121

Hokkanen H, Pimentel D (1989b) New associations in biological control: theory and practice. Can Entomol 121:829-840

Hokkanen H, Granlund H, Husberg G-B, Markkula M (1986) Trap crops used successfully to control Meligethes aeneus (Col., Nitidulidae), the rape blossom beetle. Ann Entomol Fennici 52:115-120

Hokkanen H, Husberg G-B, Söderblom M (1988) Natural enemy conservation for the integrated control of the rape blossom beetle Meligethes aeneus F. Ann Agric Fenniae 27:281-293
Hokkanen HMT, Menzler-Hokkanen I, Butt TM (2003) Pathogens of oilseed rape pests. In: Alford DV (ed) Biocontrol of Oilseed Rape Pests. Blackwell Science, Oxford, pp 299-322

Hokkanen HMT, Menzler-Hokkanen I, Lahdenperä M-L (2015) Managing bees for delivering biological control agents and improved pollination in berry and fruit cultivation. Sustain Agric Res 4, 3, 89 . https://doi.org/10.5539/sar.v4n3p89

Hornby D (1983) Suppressive soils. Ann Rev Phytopathol 21:65-85. https ://doi.org/10.1146/annurev.py.21.090183.000433

Husberg G-B, Hokkanen HMT (2001) Efects of Metarhizium anisopliae on the pollen beetle Meligethes aeneus and its parasitoids Phradis morionellus and Diospilus capito. Biocontrol 46:261-273

Lipa JJ, Hokkanen HMT (1992) Nosema meligethi I. \& R. (Microsporida) in populations of Meligethes spp. in Europe. Biocontrol Sci Tech 2:119-125

Mauchline AL, Cook SM, Powell W, Chapman JW, Osborne JL (2017) Migratory flight behaviour of the pollen beetle Meligethes aeneus. Pest Manag Sci 73:1076-1082. https://doi.org/10.1002/ps.4550

Menzler-Hokkanen I, Hokkanen HMT (2005) Developing entomopathogenic nematode delivery systems for biological control of oilseed rape pests. IOBC/WPRS Bull 28:19-22

Menzler-Hokkanen I, Hokkanen HMT (2018) Socioeconomics of adopting IPM strategies by oilseed rape farmers. EPPO Bull https://doi. org/10.1111/epp. 12498

Perälä TH (1995) Rapsikuoriainen ja sen luontaiset viholliset rypsi-apila sekakasvustossa. Pollen beetle and its natural enemies in rapeseedclover intercrop. M.Sc.-Thesis, Department of Applied Zoology, University of Helsinki, Finland, p 76

Pineda A, Kaplan I, Bezemer TM (2017) Steering soil microbiomes to suppress aboveground insect pests. Trends Plant Sci 22:770-778, https://doi.org/10.1016/j.tplants.2017.07.002

Prieto JD, Castañé C, Calvet C, Camprubi A, Battaglia D, Trotta V, Fanti P (2017) Tomato belowground-aboveground interactions: Rhizophagus irregularis affects foraging behavior and life history traits of the predator Macrolophus pygmaeus (Hemiptera: Miridae). Arthropod Plant Interact 11: 15-22, https://doi.org/10.1007/s1182 9-016-9465-5

Random House (1991) Webster's College Dictionary. Random House, New York

Roberts DW, St Leger RJ (2004) Metarhizium spp., cosmopolitan insectpathogenic fungi: mycological aspects. Adv Appl Microbiol 54:170. https://doi.org/10.1016/S0065-2164(04)54001-7

Schlatter D, Kinkel LL, Thomashow LS, Weller DM, Paulitz TC (2017) Disease suppressive soils: new insights from the soil microbiome. Phytopathology. https://doi.org/10.1094/PHYTO-03-17-0111-RVW

Schröder ML, Glinwood R, Ignell R, Krüger K (2017) The role of visual and olfactory plant cues in aphid behaviour and the development of non-persistent virus management strategies. Arthropod Plant Interact 11:1-13. https://doi.org/10.1007/s11829-016-9463-7

Shelton AM, Badenes-Perez FR (2006) Concept and applications of trap cropping in pest management. Annu Rev Entomol 51:285-308. https ://doi.org/10.1146/annurev.ento.51.110104.150959

Shikano I, Rosa C, Tan C-W, Felton GW (2017) Tritrophic interactions: microbe-mediated plant effects on insect herbivores. Ann Rev Phytopathol 55:313-331. https://doi.org/10.1146/annurevphyto-08051 6-035319

Skellern MP, Cook SM (2018) Prospects for improved off-crop habitat management for pollen beetle control in oilseed rape. Arthropod Plant Interact. https://doi.org/10.1007/s11829-018-9598-9

St Leger RJ, Allee LL, May B, Staples RC, Roberts DW (1992) Worldwide distribution of genetic variation among isolates of Beauveria spp. Mycol Res 96:1007-1015. https://doi.org/10.1016/S0953 -7562(09)80108-1

Taimr L, Sedivy J, Bergmannova E, Hanker I (1967) Further experience obtained in studies on dispersal flights of Meligethes aeneus $\mathrm{F}$., marked with P32 (Coleoptera). Eur J Entomol 64:325-332 
Thies C, Tscharntke T (1999) Landscape structure and biological control in agroecosystems. Science 285:893-895. https://doi.org/10.1126/ science. 285.5429.893

Tiilikainen TM, Hokkanen HMT (2008) Pyrethroid resistance in Finnish pollen beetle (Meligethes aeneus) populations - is it around the corner? EPPO Bull 38:99-103

Vänninen I (1996) Distribution and occurrence of four entomopathogenic fungi in Finland: effect of geographical location, habitat type and soil type. Mycol Res 100:93-101
Vänninen I, Husberg G-B, Hokkanen H (1989) Occurrence of entomopathogenic fungi and entomophilic nematodes in cultivated soils in Finland. Acta Entomol Fennica 53:65-71

Veromann E, Saarniit M, Kevvai R, Luik A (2009) Effect of crop management on the incidence of Meligethes aeneus Fab. and their larval parasitism rate in organic and conventional winter oilseed rape. Agron Res 7:548-554 